\title{
Article
}

\section{Exploring team working and shared leadership in multi-disciplinary cancer} care

\author{
Willcocks, Stephen George \\ Available at http://clok.uclan.ac.uk/19264/ \\ Willcocks, Stephen George ORCID: 0000-0002-1764-5951 (2018) Exploring \\ team working and shared leadership in multi-disciplinary cancer care. \\ Leadership in Health Services, 31 (1). pp. 98-109. ISSN 1751-1879
}

It is advisable to refer to the publisher's version if you intend to cite from the work. http://dx.doi.org/10.1108/LHS-02-2017-0011

For more information about UCLan's research in this area go to http://www.uclan.ac.uk/researchgroups/ and search for < name of research Group>.

For information about Research generally at UCLan please go to http://www.uclan.ac.uk/research/

All outputs in CLoK are protected by Intellectual Property Rights law, including Copyright law. Copyright, IPR and Moral Rights for the works on this site are retained by the individual authors and/or other copyright owners. Terms and conditions for use of this material are defined in the policies page.

\section{CLoK}

Central Lancashire online Knowledge www.clok.uclan.ac.uk

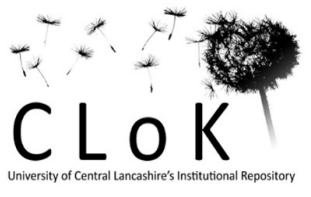




\section{Exploring team working and shared leadership in multi- disciplinary cancer care}

\begin{tabular}{|r|l|}
\hline Journal: & Leadership in Health Services \\
\hline Manuscript ID & LHS-02-2017-0011.R1 \\
\hline Manuscript Type: & Conceptual Paper \\
\hline Keywords: & Health leadership initiatives, Health services, Hospitals, Leadership \\
\hline \multicolumn{2}{|c}{} \\
\hline
\end{tabular}

\section{SCHOLARONE"}

Manuscripts 


\section{Exploring team working and shared leadership in multi-disciplinary cancer care}

This article explores team working and shared leadership in the context of multi-disciplinary cancer care in the UK NHS, in particular, its relevance to the concept of the multi-disciplinary team, (MDT). The latter has been evolving since the Calman-Hine report in 1995 and subsequent policy documents, and national guidance, and they are currently the preferred way of organising cancer care in the UK, and in other countries, (Fleissig, et al, 2006, Lamb, et al, 2011 b, Taylor et al, 2010 ). Implementation of the idea of multi-disciplinary teams has been spurred by national guidelines on clinical outcomes, and in the case of cancer, by national service frameworks for cancer care, (Taylor, et al, 2010, Carter et al, 2003, p126). Indeed, use of MDTs for specific tumour groups is now mandatory in the UK, (Lamb, et al, 2011b).

Cancer services are undergoing wider strategic change as part of new policy initiatives in the UK NHS. In order to respond to such change, and the ongoing development of multidisciplinary working, shared leadership, as opposed to traditional conceptualisations of leadership, may be worthy of further exploration. This is particularly so, given that such services have already developed collaborative organisational arrangements, for example, MDTs, cancer alliances, networks and new models of care.

The aim of this article is to explore shared leadership from the cancer service perspective. Firstly, it will look at MDTs and the policy background to shared leadership in cancer services; secondly, it will define shared leadership and assess the behaviours and attributes that might underpin it; and thirdly, it will discuss the implications and make recommendations about how to develop shared leadership in the context of multidisciplinary cancer services and the continued use of MDTs.

\section{Policy background to cancer service in the NHS}

Development of multi-disciplinary teams, (MDTs).

As noted, multi-disciplinary team working is now the accepted way of organising and delivering cancer care as recommended by the Calman-Hine report which advocated a shift in cancer services from individual working to an 'overtly multi-disciplinary model', (Haward, 2006, p338). The rationale for introducing multi-disciplinary team working is the increasing complexity of care and the consequent need for all relevant professionals to be involved in clinical decision making, (Taylor, et al, 2010). Complexity and specialisation are said to be important drivers of the development of multi-disciplinary teams in cancer service delivery, (Blazeby, et al, 2005, p1). In a European policy statement on cancer care it has been stated that 'optimal decision making in the diagnosis, treatment and support of cancer patients is being increasingly associated with multi-disciplinary teams, (MDTs)', (European Partnership Action Against Cancer consensus group, 2014, p476).

While this has been the case for some years, evidence specifically of MDT effectiveness is limited, (Fleissig, et al, 2006, p935, Taylor, et al, 2010). However, the effectiveness of teams generally has been the subject of considerable research. Borrill, et al, point out that: 
'there is substantial empirical evidence that the introduction of teamwork and group goals in diverse settings and involving diverse task types, can lead to increased effectiveness..', (Borrill, et al, (a) 2000, p364).

There is also considerable evidence that effective healthcare teams are associated with reduced clinical error, increased safety, and team member well-being, (West and Lyubovnikova, 2013, p134). Similarly, it is noted that effective team working may contribute to reduced hospitalisation, patient satisfaction, team motivation and so forth, ( Borrill, et al, 2000, (b) p 4).

Theoretical approaches have been dominated by a systems- based, input-process-output, (IPO), framework- in which teams benefit, or otherwise, from various inputs, or antecedent factors, such as the characteristics of team members and the organisational context; team processes such as leadership, decision making, and communication; and the extent to which these inputs and processes lead to the desired outputs, or, in healthcare, outcomes, (Borrill, et al, 2000, (a),p365; Haward, et al, 2003, p16; Lemieux-Charles, et al, 2006, p266, Mathieu, et al, 2008, p412, West and Lyubovnikova, 2013, p136). There are numerous characteristics of effective team working identified in the literature that may be embedded in this framework, for example, participation, emphasis on quality, support for innovation, or shared team objectives, (Poulton and West, 1999, p 10).

Studies of MDTs and their effectiveness have identified leadership as an important characteristic in the IPO framework, and one of the key factors that might be associated with enhanced performance of such teams, ( Fleissig, et al, 2006, Haward et el, 2003, Lamb, et al, 2011 a). For example, in a systematic review of decision making in MDTs, it was found that quality, patient safety and team morale are likely to depend on effective leadership , (Lamb, et al, 2011,a p2122). Conversely, in a study of the effectiveness of multi-disciplinary teams in breast cancer care, it is suggested that where there is a 'lack of clarity or conflict about leadership [this is] strongly and negatively related to effectiveness', (Haward et el, 2003, p21). Similarly, it is argued that lack of leadership or unstable leadership are among the causes of problems with team working in healthcare, (Ndoro, 2014, p727). Whether positive or negative, leadership is an important factor when considering the effectiveness of MDTs, and will be the focus of this paper.

\section{Policy development in cancer care}

Leadership is important given the wider policy background to cancer services in the UK which is rapidly evolving, the result of recent wide ranging policy reviews such as 'Achieving World Class Cancer Outcomes: A Strategy for England', ( Independent Cancer Taskforce 2015), which outlines the way forward for cancer services over the next five years and is the cancer specific strategy as part of the Five Year Forward View ( NHS England, 2014). The former strategy says that a shared approach is important determinant in making the strategy work: 'success in delivering the aspirations of this strategy will depend on devolved decision making, agility and new models of care', (Independent Cancer Taskforce, 2015,). Leadership will be required to deliver the strategy and its six strategic priorities ie upgrade in prevention and public health; earlier diagnosis; priority to patient experience; 
transformation of support for people with cancer; investing in a modern high quality service; and overhauling the processes for commissioning accountability and provision, (Independent Cancer Taskforce, 2015,).

Of particular interest in the context of a shared approach is the priority to establish Cancer Alliances bringing together commissioners, providers and patients and providing 'cancer specific leadership', (NHS England 2016, a p 4). Similarly, new models of care are premised on the importance of a shared approach such as the national Cancer Vanguard led by Christie and Royal Marsden hospitals, piloting a clinical network model, (NHS England 2016, a p18). The task forces strategy has been endorsed by the government and will guide implementation of the changes over the next five years. Operational planning and contracting guidance for 2017-2019 is to work with alliances and cancer vanguard to implement the task force report for cancer, (NHS England, b 2016). The Government has established a new national structure to implement the changes, including a National Cancer Transformation Board and Advisory Group and work stream groups overseeing the six strategic priorities.

Along with patient involvement it is envisaged that clinical leadership will play a key role in promoting these changes, particularly where this involves a 'bottom up as opposed to top down' approach to clinical leadership, (Walsh and Lynas, 2016, p8). There will be a need to ensure that the workforce in cancer services 'have the right skills, knowledge, and competence to provide high quality cancer care', (NHS England 2016 a p 15). One may argue that this includes skills, knowledge and competence in collaborative working and shared leadership.

\section{Shared leadership in cancer services}

\section{Definitions}

Leadership remains a popular solution to the problem of 'improving the quality of healthcare and the improvement of organisational processes', (Hartley and Benington, 2010, p3). However, leadership is a disputed subject area and difficult to define.

Notwithstanding this difficulty, it is possible to suggest there are at least three ways of conceptualising or defining leadership in terms of broad focus: that is, by person, position or process, (Hartley and Allison 2000, cited in Malby, et al, 2011, p341).Traditional

conceptualisations of leadership, such as traits, style or charismatic leadership, and other approaches, like authentic leadership, leadership competency, and so forth, rely on the person or position ie an individual perspective, with emphasis on top leaders who are expected to display 'heroic' characteristics and behaviours and lead the organisation forward almost single-handedly. However, it is noted that this may be problematic in circumstances where such leaders display inappropriate or unethical behaviours, ( AlimoMetcalfe and Alban- Metcalfe, 2011, p7). There is the possibility that this will result in 'divisive and dysfunctional leadership', (Lamb, et al, 2011, c p1201). In the current and future climate and given policy changes emerging, and the complexity of cancer services, individual notions of leadership may no longer be appropriate. 
More recent conceptualisations see leadership as a process 'shared by multiple individuals who may or may not be positioned at the top of the hierarchy', (McKee, et al, 2013, p12). It is premised on the fact that shared leadership involves at least two or more leaders, and that individual leaders are unlikely to possess all qualities required for effective leadership, (Bergman, et al, 2012, p18). Such conceptualisations focus on group dynamics and the process of interaction between different members of a team, each of whom may assume a leadership role according to the circumstances, although this does not necessarily preclude the co- existence of positional leadership within a team. This allows for the fact that leaders may emerge in organisations when 'they are needed, when their relevant skills, knowledge and expertise are required by the team', (Bergman, et al, 2012, p18). When they are not being a leader they are followers, and 'followership' rather than a leader-centric approach, is said to be important in healthcare, (Mannion, et al, 2015, ).

While defining shared leadership has proved difficult there is some agreement in the literature that it is:

'a relational, collaborative leadership process or phenomenon involving teams or groups that mutually influence one another and collectively share duties and responsibilities otherwise relegated to a single leader', (Kocolowski, 2010, p24).

This definition supports the emphasis on the process, but also suggests the importance of horizontal, as opposed to vertical relationships between leader and follower and this has become increasingly relevant in the NHS as more emphasis is attached to concepts such as partnership working, collaboration, and inter-professional team working. This is the case with regard to the organisation and delivery of cancer care but it applies generally to healthcare delivery. It is said that health care organisations are receptive to shared leadership as the quality of care may be affected by the presence or otherwise of effective collaborative working between different professionals working towards a common goal, (Kocolowski, 2010, p26). Emphasis on collaborative working may be particularly relevant in cancer care. Fennell, et al, point out that:

'quality cancer care is complex and depends upon careful coordination between multiple treatments and providers and upon technical information exchange and regular communication flow between all those involved in treatment', (Fennell, et al, 2010, p72).

Complexity makes it difficult for a single leader to be effective, hence the shift to shared leadership whereby tasks may be distributed according to expertise or skill, (Kunzle et al, $2010, p 1)$. Shared leadership is said to be important 'when dealing with complex tasks in which the active engagement of multiple team members may be critical in solving a problem', (Bligh, et al, 2006, p309). Similarly, shared leadership may be effective where work tasks are highly interdependent, complex and depend on creativity, (Hartley and Benington, 2010, p33). These criteria may resonate with the work of MDTs, indeed, involvement in complex problem-solving and decision making is the raison d'etre of such teams.

Thus shared, as opposed to individual conceptualisations, of leadership, may be seen as an appropriate way forward in the context of cancer care, particularly given the continuing 
emphasis on multi-disciplinary teams. This is supported by Haward, et el, 2003, in a study of breast cancer teams, who found that 'teams with shared leadership of their clinical decision making were most effective', (Haward et el, 2003, p 15). While adopting shared leadership may be the way forward, it may also be problematic as it involves a transition from traditional, individualised clinical care and professional autonomy to new emphasis on shared care and expertise provided by clinical teams, (Willard, and Luker 2007, p719). On the other hand, where this transition is successful, it has been reported that teams with shared leadership have 'less conflict, greater consensus, and higher intragroup trust and cohesion', (Bergman, et al, 2012, p34).

\section{Leadership behaviours and attributes for shared leadership}

Definitions of shared leadership emphasise that it is a process whereby leadership is shared within the group but it is also important to identify just what is shared ie what constitutes the activity, skills, expertise or behaviour that is shared by group members. It has been said that this aspect - 'the leadership qualities of whole teams'- has been neglected in the literature, (Hartley and Benington, 2010, p84). This question has multiple answers depending on the perspective taken and is by no means agreed.

One possibility, taken up by Bergman, et al, although not in a health care context, is that of generic leadership behaviours based on the work of Yukl, and Sundstrom, De Meuse, and Futrell ,(Bergman, et al, 2012). These behaviours and underpinning skills will be explored further in the context of cancer care and the MDT, although it is noted that they are by no means a definitive list of behaviours,(Bergman, et al, 2012). Hence, within a team it is suggested that there are at least four generic categories of leadership behaviour that may be shared: initiating structure behaviours (task- oriented); consideration behaviours (relations-oriented); envisioning behaviours (change oriented); and spanning behaviours (oriented towards dealing with the boundary between team and wider organisation), (Bergman, et al, 2012, p19). Leaders need to be adaptive in their choice of such behaviours, and underpinning skills, depending on the needs of their followers and the organisation, (Mannion, et al, 2015, p270).

It can be argued that the first two - task and relations- oriented - behaviours - are complimentary, in that they are concerned with achieving the core tasks of the MDT - such as diagnosis, and treatment/ rehabilitation goals - and at the same time, ensuring that relationships and interactions within the team are conducive and supportive of these goals. While individual leaders may have a preference for a particular behaviour, the advantage of adopting shared leadership is that a range of behaviours may be available to the MDT, depending on team members and the context or task. A task- oriented style may, in fact, be provided by a positional or hierarchical leader within the team. McKee, et al suggest there may be a need for 'old style' leadership providing direction and focusing on tasks, to counter balance other approaches, ( McKee et al, 2013, p17).

Adopting task -oriented leadership behaviour means that leaders of MDTs are likely to engage in activities like planning, organising, monitoring, coordinating, forecasting and goal setting. These underpin the more traditional leadership functions and, as such, may overlap 
with classical definitions of management. The leaders' effectiveness in adopting these behaviours may depend on underpinning cognitive, analytical, technical and organisational skills and knowledge and understanding of the context. However, it has been stated that there is now a shift away from this approach to leadership, although both approaches may still be required:

'[.. ]after many years acknowledging the importance of task and more cognitive- oriented conceptions of health leadership, the balance appears now to be switching towards an understanding of the importance of the emotional and relationship dimension', (Skinner and Spurgeon, 2005, p11).

The latter dimension is important in cancer care, not least because problems relating to relationships within the MDT may have an adverse effect on patient care. One reported problem is that some team members felt excluded or marginalised, particularly nurses, (Lamb, et al, 2011 b p1975). Similarly, a study noted the problem of hospital cancer nurse specialists not being accepted by medical colleagues, and other members of the team, (Willard and Luker, 2007, p712). In another study of MDT coordinators in multi-disciplinary cancer teams it was reported that coordinators felt that they 'neither contribute to the MDT discussion nor their opinions carry weight', (Jalil, et al, 2012). These problems may be compounded by other issues, such as the levels of stress and burnout in staff working in cancer care, (Black and Westwood, 2004, p578).

In such circumstances, leaders of MDTs may adopt relations- oriented leadership behaviour, for example, showing consideration, nurturing and supporting team members from differing professional backgrounds, taking account of individual and group needs, and ensuring a contribution from all team members. The leaders' effectiveness in this aspect of their role may be underpinned by their communication skills, (Lamb, et al, 2011, c p1201). Similarly, one may suggest that emotional intelligence (EQ) is important and enables the leader to demonstrate 'awareness of the feelings, moods and emotions of oneself and others, and the ability to act in ways that contribute to goal formulation and goal achievement', (Hartley and Benington, 2010, p p81). This is said to be particularly important in an era where various inquiries into scandals in the NHS, for example, the Francis Inquiry, have highlighted that there is a pressing need to take more account of the emotional dimension in healthcare, ( O' Sullivan, and McKimm, 2014, p283).

The third set of generic behaviours- change- oriented, or envisioning, behaviours- are also important for leaders seeking group support for the development of vision, ideas, and goals, (Bergman, et al, 2012, p19). These may provide the MDT with the capacity to respond to change or be innovative in the delivery of care and also facilitate change in clinical practice. Receptiveness to change is imperative in cancer care where the translation of research into practice is vital. Such change may be triggered internally, or as a result of external policy changes like those described earlier. In a study of upper gastro-intestinal cancer MDTs the authors argue that 'team working represents a potentially powerful lever for change', (Blazeby, et al, 2005, p3). The ability to lead such teams by adopting appropriate, changeoriented behaviours is particularly apposite in the context of an NHS currently in the process of implementing major policy change, not least in cancer care. 
While such behaviours may be provided by a formally appointed leader of the team such as the Chairperson or MDT coordinator, they may also be provided by a team member who has a special interest and expertise in the proposed change. Indeed, it is suggested that the leadership or influencing role during periods of change 'passes, informally or at different phases, between different individuals and groups, with differing bases of expertise and legitimacy at different times, (Hartley and Benington, 2010, p33). The leaders' effectiveness in the influence process may be underpinned by transformational leadership ie idealised influence; inspirational motivation; intellectual stimulation; and individualised consideration, (Northouse, 2004). There is some overlap here with the generic leadership behaviours so far described, for example, 'individual consideration' is similar to relationoriented behaviours. Of interest in the context of change is the emphasis on motivating and stimulating different members of the team, and encouraging 'innovative and creative behaviour', (Willcocks, 2016, p227).

Finally, given that MDTs are likely to function as part of a wider network of similar teams both within and outside the immediate organisation leaders may need to adopt spanning behaviours to facilitate collaboration and cooperation with other teams and other organisations. Patkar, et al, report that the latter is a potential challenge for the MDT, for example, in establishing 'reliable interfaces with primary care to ensure continuity of care', (Patkar, et al, 2011, p4). This is increasingly important with the onset of various collaborative initiatives in healthcare generally, and cancer services in particular, such as the development of cancer alliances and networks spanning across provider organisations delivering care. Fitzgerald, et al, suggest that the 'boundary spanner' role may be exercised by 'clinical hybrids', that is those staff occupying both clinical and managerial roles, (Fitzgerald, et al, 2013, p236).

Regardless of who occupies the role of 'boundary spanner' within the MDT, one may argue that the leaders' effectiveness in this may be underpinned by skills associated with 'connective leadership'. This involves the leader in creating:

' inter- connections between and across practice settings, the purpose of which is to better coordinate and integrate patient care services in a caring, non- competitive, collegial manner', (Gopee and Galloway, 2009, p56).

It has been suggested, in a study of breast cancer, that breast cancer nurses may act as a lynch pin for the MDT, providing information that connects the work of the team with other 'treatment modalities' outside of the MDT, (Amir, et al, 2004, p313). In this role they may be acting as 'boundary spanner' for the MDT. It can be noted, however, that there is some debate about which specialties tend to be predominately involved in the leadership of MDTs, and, as stated earlier, whether some may be excluded, (Lamb, et al, 2011 c, p1206).

In general, it has been concluded that the likelihood of a team experiencing a full range of leadership behaviour [such as the above] increases to the extent that multiple team members share leadership', (Bergman, et al, 2012, p34). The suggestion is that each of these various behaviours and underpinning skills and attributes may be demonstrated by different members of the MDT, some may be formally appointed, such as the Chairperson or 
Coordinator, but others may emerge as the most suitable leader depending on the activity, the circumstances, and the expertise/ skills of the individual team member. In a study of the role of breast cancer nurses it suggested that this professional group may emerge as 'the informal leaders of the team', (Amir, et al, 2004, p310). Lamb, et al, believe it is not so much the clinical specialty of the team member as the possession or otherwise of 'interpersonal, non- technical skills', suggesting that leadership could be exercised by any member of the team, (Lamb, et al, 2011, p1201).

\section{Implications / recommendations}

While shared leadership may lead to a cohesive multi-disciplinary team, with collegial working relationships and strong sense of purpose, as stated, it is not easy to achieve as it may involve a transition from traditional ways of working and divergence from traditional norms and professional values. As noted by Fennell, et al:

'different medical specialties and affiliated professionals are all subject to the specific norms and expectations of their own professional groups and these do not always align, ' (Fennel, et al, 2010, p76).

Developing shared leadership in the context of MDTs requires a shift away from traditional ways of leadership where leadership is assumed by one person, who may be the appointed leader ie positional leadership. While there may still be a role for the latter within the MDT, there is a need to make more use of the leadership behaviours, and underpinning abilities and expertise of different team members. This is particularly apposite in the context of an MDT involved in cancer care which typically comprise various highly trained clinicians from different professional backgrounds and training such as consultants and supporting junior staff in radiotherapy, oncology and surgery, radiographers, other allied health professionals and specialist nurses.

Such staff are a key resource for the team and provide a source of shared learning, education and development, (Taylor, et al, 2010). Shared learning is particularly important given criticism of healthcare organisations that they have failed to learn from the past and need more reflective leadership, (Hartley and Benington, 2010, p71). The latter may be more likely with shared leadership given its emphasis on participation and interaction within the team. As a resource it can contribute to an improved clinical decision making process informed by the full range of expert knowledge within the team. This is supported by Whelan, et al, in a study of breast cancer MDTs, who report that clinical decision making is most effective in MDTs with a shared leadership style', (Whelan, et al, 2006, p121). Similarly, Haward, et al report that 'teams with shared leadership of their clinical decision making were most effective', (Haward, et al, 2003, p15).

Given that shared leadership relies on participation it is also likely to have the effect of empowering and motivating staff, which in turn is likely to stimulate greater creativity and innovative solutions to problems. The latter is an espoused aim of the reforms currently underway in the NHS and is relevant particularly to MDTs involved in cancer care. Shared leadership is also said to provide a 'mutually supportive environment' for team members, (Fleissig, et al, 2006, p937). This suggests that shared leadership may contribute to the 
mental health well -being of the team. However, it is important to ensure clarity in the leadership process as without this there is a risk of inertia in decision making or confusion about who is responsible for particular initiatives. In other words, it is important to avoid a situation where there may be a leadership vacuum where no one assumes a leadership role within the MDT.

Shared leadership may also be enhanced by organisational factors that contribute to collaborative working of MDTs, such as information flow, IT, coordination and communication mechanisms, and the availability of time and admin support. Equally, where these are not provided, or they are inadequate, there may be an adverse effect on the process of shared leadership. With regard to communication, this may be aided by shared leadership although 'conflict over leadership and lack of clarity about leadership were both negative predictors of effective internal communications', (Fleissig, et al, 2006, p939).

It has been stated that possible solutions to some of these problems include greater attention to job planning, development/training opportunities in leadership and team working skills, and ensuring team members, particularly nurses, are not excluded from the decision making process, (Lamb, et al, 2011,a p2123). . Shared leadership is likely to work where there is 'planning as well as cultural change and strong commitment', (Konu and Viitanen, 2008, p36). With regard to development and training, this partly depends on the extent to which team members, individually and collectively, possess certain behaviours, and underpinning skills, knowledge and so forth, to lead the team, for example, personal qualities and human relations skills that are important in team leadership. It can be argued that as leadership roles may be shared there is less need for all the above attributes to be developed across the team. But development may be required, both in terms of acquisition of individual behaviours, skills, etc, and also team development, ensuring the team works collegially in achieving team goals. A focus on the latter, more than the individual, is said to be important as a means of addressing 'wicked' (difficult) problems in healthcare, (Edmonstone, 2014, p463).

Just as important as these initiatives will be measures to ensure that the culture of the organisation is supportive and encouraging of new ways of working which rely less on traditional conceptualisations of leadership and more on the philosophy of shared leadership. It is important to ensure that all team members are nurtured and supported in their leadership role. This involves adhering to different views about the way in which decisions are made in MDTs and the way in which power is devolved to the level of the team. It has been suggested that there is a developmental challenge in overcoming traditional 'rigid hierarchy of power and influence' in healthcare organisations, \{Black and Westwood, 2004, p577).

Organisations need to pay particular attention to the latter and the more general issue of facilitating cultural change. They may do this by various means such as providing training that is based on shared learning and a multi-disciplinary ethos. More generally, organisations may need to pay attention to their style of leadership and governance and the way in which clinical staff are integrated, or otherwise, into the running of the organisation. A large scale study of leadership in the NHS identified key themes that need to be 
considered: supporting and respecting others, developing team working, removing barriers to communication, encouraging a questioning approach, and 'promoting behaviour that encourages the creation of a culture supporting people's personal development', (AlimoMetcalfe and Bradley, (2009). One may argue the latter is particularly important in the context of developing effective multi-disciplinary team working and leadership in cancer care.

At a national level, there may be a need to pay more attention to the way in which clinicians are trained in their undergraduate schools, with more emphasis on shared learning and exposure to multi-disciplinary team working and leadership early on in their training.

Research Implications

Case study- based research may be needed to test the ideas in this paper. Such research may explore leadership and team working in specific multi-disciplinary teams in cancer care, that is specific tumour groups. It has been noted that while there is research on team effectiveness generally, 'research evidence on the benefits [specifically] of MDT working is sparse', (Fleissig, et al, 2006, p937). However, research may be problematic as it is suggested that not all teams are 'real teams' in terms of having team characteristics such as shared objectives and interdependent working, and may be described as 'pseudo teams', (West and Lyubovnikova, 2013, p136).

One issue may in fact be addressing the problem of whether an MDT is a 'pseudo team' or a real team, and if the former, exploring ways of how to make the transition to a real team. West and Lyubovnikova suggest that research needs to 'better describe' teams in terms of real team characteristics, ( West and Lyubovnikova, 2013,p139). Another issue has already been suggested, that is, the contribution of different team members may be problematic, (Lamb, et al, 2011, p1975, Willard and Luker, 2007, p712). Research may be needed to explore the reasons for this perceived problem.

Other issues that may be researched include the leadership behaviours and underpinning skills and knowledge required by team members, the barriers to team working, and the role power and authority play in enhancing or inhibiting team work and leadership. The latter is of particular interest. Research may be needed to explore the extent to which the culture of the MDT, and the culture of the professions generally, acts as a facilitator or barrier to effective team working and leadership. Such research will need to include qualitative research to facilitate understanding of the perceptions, emotions, and subjective meanings held by those actually involved in team work settings in multi -disciplinary cancer care.

\section{Conclusion}

This article has explored shared leadership in the context of multi-disciplinary cancer services in the UK. It has suggested that this may be an appropriate way forward in developing leadership of such services, particularly as they have already adopted collaborative models of care.

While the policy and organisational context lends itself to the adoption of shared leadership, the latter is not without problems as it involves a transition to new ways of working and 
decision making. These may be surmounted by attending to structural and cultural aspects of cancer care delivery and facilitating acceptance of a shared approach. In particular, the leadership behaviours, and underpinning expertise and attributes of individual team members in cancer care need to be nurtured and developed and made available for the benefit of the MDT as a whole.

Shared leadership is not the only way forward for improving services in cancer care but it is worthy of exploration and further research in the context of the MDT and other collaborative initiatives. Given the complexity of such services described earlier shared leadership is an important aspect requiring attention when considering the organisation and delivery of cancer care services.

\section{References}

Amir, Z, Scully, J, and Borrill, C, ( 2004), The professional role of breast cancer nurses in multi-disciplinary breast cancer teams, European journal of Oncology nursing 8 pp306-314 Alimo-Metcalfe, B and Bradley, M (2009) Cutting Crew, Health Service Journal, 7 May, 8-9

Alimo- Metcalfe, B and Alban-Metcalfe, J ( 2011),The need to get more for less: a new model of engaging leadership and evidencve of its effects on team productivity and staff morale and well being at work, CMI London pp6-13

Bergman, J Z, Rentsch, J R, Small, E E, Davenport, S W, and Bergman, S M, (, 2012), The shared leadership process in decision-making teams The Journal of Social Psychology, 152:1 pp 17-42

Black, TG, Westwood, M J ( 2004), Evaluating the development of a multi-disciplinary leadership team in a cancer centre, Leadership and Organisational Development journal, vol 25,7, pp577-591

Blazeby, J M, Wilson, L, Metcalfe, C Nicklin, J, English, R and Donavan, J L. ( 2005), Analysis of clinical decision-making in multi-disciplinary cancer teams, Annals of Oncology 10 pp1-4

Bligh, M C, Pearce, C L, and Kohles, J C, ( 2006), The importance of self and shared leadership in team based knowledge work, Journal of Managerial Psychology, 214 pp296318

Borrill, C, West, M, Shapiro, D, and Rees, A, (2000) Team working and effectiveness in healthcare, British Journal of Healthcare Management, Vol 6, 3 pp 364-371, (a)

Borrill, C S, Carletta, J, Carter A J,Dawson, J F, Garrod, S, Rees, A, Richards, A, Shapiro, D, and West, M A, (2000)The Effectiveness of Health Care Teams in the NHS, (b) Available from: http://ctrtraining.co.uk/documents/TheEffectivenessofHealthCareTeamsintheNHS_004.pdf Carter, S, Garside, P, and Black, A,( 2003), Multi-disciplinary team working, clinical networks and chambers; opportunities to work differently in the NHS, Qual Saf Healthcare 12 pp25-28 Edmonstone, J ( 2014), Effective medical leadership development for a complex NHS, British Journal of Hospital Medicine, August, Vol 74, 8 pp461-463 
Fitzgerald, L, Ferlie, E, McGivern, G, and Buchanan, D, ( 2013 ), Distributed leadership patterns and service improvement: evidence and argument from English healthcare, The Leadership Quarterly, 24 pp 227-239

European Partnership Action Against Cancer consensus group, (2014), Policy statement on multi-disciplinary cancer care, European Journal of Cancer, 50 475-480

Fennell, M L, Prabhu Das, I, Clauser, S, Petrelli, N and Sainer, A, (2010), The organisation of multi-disciplinary care teams: modelling internal and external influences on cancer care quality, Journal of the National Cancer institute Monographs 40 pp72-80 2010,

Fleissig, A, Jenkins, V, Catt, S and Fallowfield, L, (2006) Multi-disciplinary teams in cancer care: are they effective in the UK? Lancet Oncol, 7 pp935-43

Gopee, N and and Galloway, J ( 2009), leadership and management in healthcare, Sage London

Hartley, J and and Benington, J (2010) Leadership for healthcare, The Policy press, Bristol

Haward, R A, (2006), The Calmin-Hine report: a personal retrospective on the UKs first comprehensive policy on cancer services, Health care research,7 pp336- 346

Haward, R, Amir, Z, Borrill, C, Dawson, J, Scully, J, West, M, and Sainsbury, R, (2003), Breast cancer teams: the impact of constitution, new cancer workload, and methods of operation on their effectiveness, British journal of Cancer, 89 15-22 2003

Independent Cancer Taskforce, (2015) 'Achieving World Class Cancer Outcomes: A Strategy for England', (2015),July, Available at:

http://www.cancerresearchuk.org/sites/default/files/achieving_world-

class_cancer_outcomes_-_a_strategy_for_england_2015-2020.pdf

Konu, A and Viitanen, E ( 2008) Shared leadership in Finnish social and healthcare, Leadership in Health Services, Vol 21, 1 pp 28-40

Jalil, R, Lamb, B, Russ, S, Sevdalis, N, and Green, J S A, (2012), The cancer multi-disciplinary team from the coordinators perspective: results from a national survey in the UK, BMC Health services Research 12457

Kocolowski, M D, ( 2010) shared leadership: is it time for a change? Emerging leadership Journeys, Vol 3, 1 pp22-32

Kunzle, B, Zala-Mezo, E, Wacker, J, Kolbe, M, Spahn, D R, and Grote, G, ( 2010) leadership in anaesthesia teams: the most effective leadership is shared, Quality Saf Health Care pp1-6

Lamb, B W, Brown, K F, Nagpal, K, Vincent, C, Green, J S A, and Sevdalis, N, ( 2011 a), Quality of care management decisions- by multi-disciplinary cancer teams: A systematic review, Annals of Surgical Oncology, 18 pp 2116-2125

Lamb, B W, Sevdalis, N, Arora, S, Pinto, A, Vincent, C, and Green, J S A, (2011b), Teamwork and team decision making at multi-disciplinary cancer conferences: barriers, facilitators and opportunities for improvement, World J Surg, 35 1970-76 
Lamb, B, Payne, H, Vincent, C, Sevdalis, N and Green, J S A, (2011 c), The role of oncologists in multi-disciplinary cancer teams in the UK: an untapped resource for team leadership, Journal of Evaluation in Clinical Practice, 17 1200-1206

Lemieux-Charles, L, and McGuire, W L, (2006), What do we know about healthcare team effectiveness? A review of the literature, Medical Care Research and Review, Vol 63, no 3 June pp263-300

Malby, R Edmonstone J, Ross, D and Wolfenden, N,(, 2011), Clinical leadership: the challenge of making the most of doctors in management, British Journal of Hospital Medicine, 72, 6, pp341-345

Mannion, H, McKimm, J, and O'Sullivan, H, (2015), Followership, clinical leadership and social identity, British Journal of Hospital Medicine, May, Vol 76, 5, pp270-274)

Mathieu, J, Maynard, M T, Rapp, T, and Gilson, L, (2008), Team effectiveness 1997-2007: A review of recent advancements and a glimpse into the future, Journal of Management, Vol 34. 3, June, pp 410-476

McKee, L, Charles, K, Dixon-Woods, M, Willars, J, and Martin, G, ( 2013), New and distributed leadership in quality and safety in healthcare, or old and hierarchical? An interview study with strategic stakeholders, Journal of Health Services research and Policy, 182 pp 11-19

Ndoro, S, (2014), Effective multi-disciplinary working: the key to high quality care, British Journal of Nursing, Vol 23 13, pp 724-727

NHS England (2016 a), Achieving world class cancer outcomes: taking the strategy forward, May, NHS England, Leeds

NHS England (2016, b) NHS Operational planning and contracting guidance for 2017-2019, NHS England and NHS Improvement, Leeds 22 September

NHS England, (2014) Five Year Forward View, October, NHS England, Leeds

Northouse, P G,(2004) Leadership Theory and Practice, Sage London

O' Sullivan, $\mathrm{H}$ and McKimm, J, ( 2014), The role of emotion in effective clinical leadership and compassionate care, British Journal of hospital medicine, May, Vol 75, 5, pp281-286

Patkar, V, Acosta, D, Davidson, T, Jones, A, Fox, J, and Keshtgar, M, ( 2011), Cancer multidisciplinary team meetings: evidence, challenges, and the role of clinical decision support technology, International Journal of Breast Cancer, Vol 2011 pp1-7

Poulton, B, C, and West, M A, (1999), The determinants of effectiveness in primary health teams, Journal of Interprofessional Care, 13. 1. Pp 7-18

Skinner, C and Spurgeon, P (2005), Valuing empathy and emotional intelligence in health leadership: a study of empathy, leadership behaviour and outcome effectiveness', Health Services Management Research, 18, 1 pp1-12 
Taylor, C, Munro, A J, Glynne-Jones, R, Griffith, C, Trevatt, P, Richards, M and , Ramirez, A J, (2010), Multi-disciplinary team working in cancer: what is the evidence? BMJ, 340 ?

Walsh, K and Lynas, K, editorial, ( 2016), Clinical leadership and quality improvement: vital for good health care, British journal of hospital medicine, January, Vol 77, 1 p8-9

West, M, and Lyubovnikova, J, (2013), Illusions of team working in healthcare, Journal of healthcare organisation and management, Vol 27 No 1 pp 134-142

Whelan, J M, Griffith, CD M, and Archer, T ( 2006) Breast cancer multi-disciplinary teams in England: much achieved but still more to be done, The Breast, 15 pp119-122

Willard, C and Luker, K ( 2007), Working with the team: strategies employed by hospital nurse specialists to implement their role, Journal of Clinical Nursing, 16, 4 pp 716-724

Willcocks, S G, (2016) The leadership role of psychiatrists in the NHS, British Journal of Healthcare Management, Vol 22 9, pp225-230 